\title{
Chemical-biological characterization of a cruzain inhibitor reveals a second target and a mammalian off-target
}

\author{
Jonathan W. Choy ${ }^{1,2,3}$, Clifford Bryant ${ }^{1,2}$, Claudia M. Calvet ${ }^{4,5,6}$, \\ Patricia S. Doyle ${ }^{4,5}$, Shamila S. Gunatilleke ${ }^{4,5}$, Siegfried S. F. Leung ${ }^{2}$, \\ Kenny K. H. Ang ${ }^{1,2}$, Steven Chen ${ }^{1,2}$, Jiri Gut ${ }^{4,5}$, Juan A. Oses-Prieto ${ }^{2}$, \\ Jonathan B. Johnston ${ }^{2}$, Michelle R. Arkin ${ }^{1,2,4}$, Alma L. Burlingame ${ }^{2}$, \\ Jack Taunton ${ }^{3}$, Matthew P. Jacobson ${ }^{2}$, James M. McKerrow 4,5 , \\ Larissa M. Podust ${ }^{4,5}$ and Adam R. Renslo ${ }^{* 1,2,4}$
}

\section{Full Research Paper}

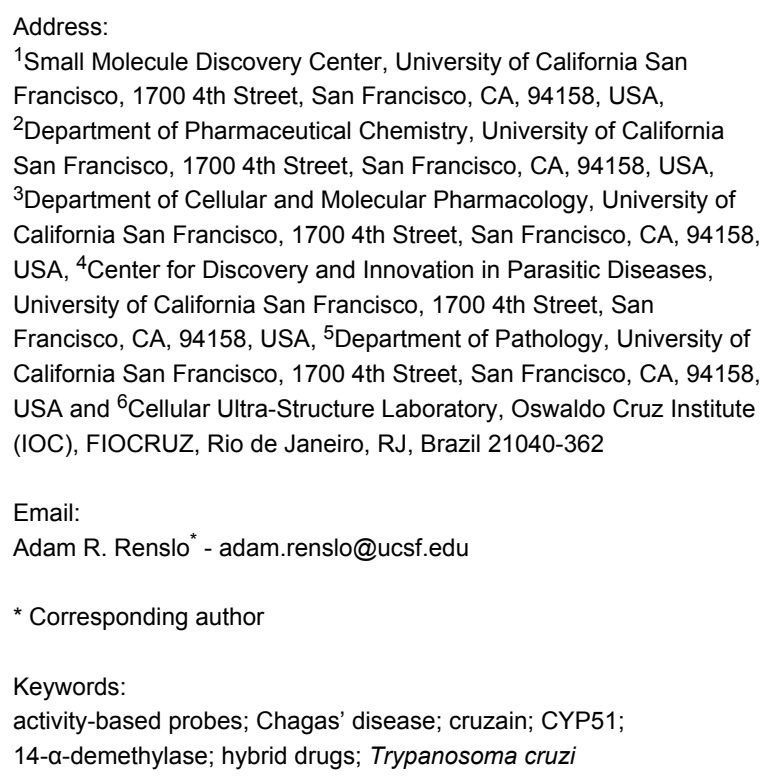

${ }^{1}$ Small Molecule Discovery Center, University of California San Francisco, 1700 4th Street, San Francisco, CA, 94158, USA, ${ }^{2}$ Department of Pharmaceutical Chemistry, University of California San Francisco, 1700 4th Street, San Francisco, CA, 94158, USA, ${ }^{3}$ Department of Cellular and Molecular Pharmacology, University of California San Francisco, 1700 4th Street, San Francisco, CA, 94158, USA, ${ }^{4}$ Center for Discovery and Innovation in Parasitic Diseases, University of California San Francisco, 1700 4th Street, San Francisco, CA, 94158, USA, ${ }^{5}$ Department of Pathology, University of California San Francisco, 1700 4th Street, San Francisco, CA, 94158, USA and ${ }^{6}$ Cellular Ultra-Structure Laboratory, Oswaldo Cruz Institute (IOC), FIOCRUZ, Rio de Janeiro, RJ, Brazil 21040-362

Email:

Adam R. Renslo* - adam.renslo@ucsf.edu

* Corresponding author

Keywords:

activity-based probes; Chagas' disease; cruzain; CYP51;

14-a-demethylase; hybrid drugs; Trypanosoma cruzi

Beilstein J. Org. Chem. 2013, 9, 15-25. doi:10.3762/bjoc.9.3

Received: 01 October 2012

Accepted: 27 November 2012

Published: 04 January 2013

This article is part of the Thematic Series "Synthetic probes for the study of biological function".

Guest Editor: J. Aube

(C) 2013 Choy et al; licensee Beilstein-Institut. License and terms: see end of document.

\footnotetext{
Abstract

Inhibition of the Trypanosoma cruzi cysteine protease cruzain has been proposed as a therapeutic approach for the treatment of Chagas' disease. Among the best-studied cruzain inhibitors to date is the vinylsulfone K777 (1), which has proven effective in animal models of Chagas' disease. Recent structure-activity studies aimed at addressing potential liabilities of 1 have now produced analogues such as $N$-[(2S)-1-[[(E,3S)-1-(benzenesulfonyl)-5-phenylpent-1-en-3-yl $]$ amino]-3-(4-methylphenyl)-1oxopropan-2-yl]pyridine-4-carboxamide (4), which is trypanocidal at ten-fold lower concentrations than for $\mathbf{1}$. We now find that the trypanocidal activity of $\mathbf{4}$ derives primarily from the inhibition of $T$. cruzi 14 - $\alpha$-demethylase (TcCYP51), a cytochrome P450
} 
enzyme involved in the biosynthesis of ergosterol in the parasite. Compound $\mathbf{4}$ also inhibits mammalian CYP isoforms but is trypanocidal at concentrations below those required to significantly inhibit mammalian CYPs in vitro. A chemical-proteomics approach employing an activity-based probe derived from $\mathbf{1}$ was used to identify mammalian cathepsin B as a potentially important off-target of $\mathbf{1}$ and $\mathbf{4}$. Computational docking studies and the evaluation of truncated analogues of $\mathbf{4}$ reveal structural determinants for TcCYP51 binding, information that will be useful in further optimization of this new class of inhibitors.

\section{Introduction}

The kinetoplastid protozoan Trypanosoma cruzi is the causative agent of Chagas' disease, a leading cause of heart failure in endemic regions of Latin America [1]. The parasite is transmitted by the reduviid bug and the disease manifests in an initial acute phase, followed by a chronic phase that can last decades and typically culminates in heart failure. The existing treatment for Chagas' disease involves extended therapy with nifurtimox or benznidazole, both of which are associated with undesirable side-effects and have limited efficacy against the chronic stage of the disease [2,3]. This situation has spurred the search for more effective and better tolerated therapeutics [4-6]. Among a number of drug targets being investigated are cruzain [7-10], the major cysteine protease active in the parasite, and T. cruzi CYP51 (TcCYP51), a 14- $\alpha$-demethylase enzyme of the cytochrome $\mathrm{P} 450$ family required for ergosterol biosynthesis [11-14]. TcCYP51 is analogous to the fungal enzyme targeted by the azole class of antifungals, and the observation that some of these drugs (e.g., posaconazole) also inhibit TcCYP51 has led to their preclinical and clinical investigation as potential new treatments for Chagas' disease $[2,15,16]$.

Cruzain is a cathepsin-L-like protease of the papain family thought to be important for intracellular replication and differentiation of the T. cruzi parasite [17]. A variety of small-molecule cruzain inhibitors have been described, the majority of which act irreversibly by reaction with the catalytic cysteine in the enzyme active site [18-27]. One of the earliest cruzain inhibitors identified and perhaps the best studied to date is the vinysulfone K777 (1, Figure 1). This irreversible inhibitor has demonstrated efficacy in animal models of Chagas' disease $[28,29]$ and continues to undergo preclinical evaluation leading towards a possible human clinical trial.

Despite many favorable properties, some aspects of $\mathbf{1}$ are suboptimal from a drug-development perspective. For example, compound $\mathbf{1}$ is known to be a mechanism-based (irreversible)

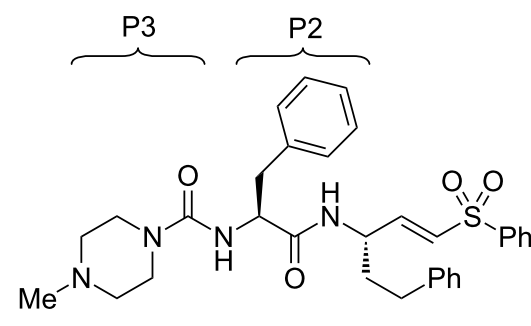<smiles>O=S(=O)(CCC(CCP)CCP)c1ccccc1</smiles><smiles>CC1CCC(C(=O)N[C@@H](Cc2c[nH]c3ccccc23)C(=O)Nc2ccncc2)CC1</smiles>

(R)- 5<smiles>[R]c1ccc(C[C@H](NC(=O)c2ccccn2)C(=O)N[C@H](/C=C/S(=O)(=O)c2ccccc2)CCc2ccccc2)cc1</smiles>
$2(\mathrm{R}=\mathrm{H})$ $3(\mathrm{R}=\mathrm{Me})$<smiles>[3H]</smiles>
(dihydro 3)

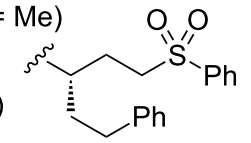<smiles>CNC(=O)[C@H](Cc1ccc(C)cc1)NC(=O)c1ccncc1</smiles>

12<smiles>Cc1ccc(C[C@H](NC(=O)c2ccncc2)C(=O)N[C@H](/C=C/S(=O)(=O)c2ccccc2)CCc2ccccc2)cc1</smiles>

4

(dihydro 4)<smiles>CC(C)CCS(=O)(=O)c1ccccc1</smiles><smiles>Cc1ccc(C[C@H](NC(=O)c2ccncc2)C(=O)NC(C)c2ccccc2)cc1</smiles>

13

Figure 1: Chemical structures of vinylsulfone-based cruzain inhibitors 1-4, known TcCYP51 inhibitor 5, dihydro controls 6-8, and truncated analogues 12 and 13. The "P2" and "P3" side chains of 1 are labeled and bind, respectively, in the S2 and S3 sub-sites of the cruzain active site. 
inhibitor of CYP3A4, an enzyme responsible for the metabolism of many drugs, including 1 itself [30]. In pharmacokinetic studies, compound $\mathbf{1}$ exhibits nonlinear exposure with escalating dose and is known to be a substrate of the drug transporter P-glycoprotein (P-gp). Finally, as a basic (protonatable) drug species, 1 could potentially accumulate in acidic lysosomes, where mammalian cathepsins (potential off-targets of $\mathbf{1}$ ) are located. The issue of lysosomotropism figured prominently in the discovery and clinical development of cathepsin K inhibitors for osteoporosis. The first such inhibitor to successfully navigate human clinical trials is odanacatib, which was intentionally designed as a nonbasic drug species to minimize the potential for lysosomotropic behavior $[31,32]$.

We sought to address the question of lysosomotropism by preparing analogues of $\mathbf{1}$ in which the basic piperazine substituent at "P3" (which binds the S3 subsite of cruzain) was replaced with nonbasic or weakly basic heterocycles. In our initial structure-activity study [21], we found that analogue 2 (Figure 1), bearing a 2-pyridylamide at the $\mathrm{P} 3$ position, possessed trypanocidal activity that was on par with $\mathbf{1}$ (Table 1). However, none of the nonbasic analogues examined proved superior to 1 and only 2-pyridyl analogues such as $\mathbf{2}$ and $\mathbf{3}$ appeared even comparable. We therefore turned to more dramatic structural alteration and successfully identified and structurally characterized a new nonpeptidic cruzain inhibitor chemotype [24]. Most recently, we returned to reinvestigate nonbasic analogues of $\mathbf{1}$ and now report that 4-pyridyl analogues such as $\mathbf{4}$ (Figure 1) are significantly more trypanocidal than $\mathbf{1}$ or $\mathbf{2}$, and unexpectedly exert their trypanocidal effects primarily by inhibition of TcCYP51 rather than cruzain.

\section{Results and Discussion \\ Structure-activity studies}

Our exploration of the $\mathrm{P} 3$ position in $\mathbf{1}$ included the evaluation of regioisomeric 2-, 3-, and 4-pyridyl congeners in the context of various P2 side chains. In many such analogue series, we found that regioisomeric analogues possessed similar cruzain activities in vitro, while the 4-pyridyl examples consistently demonstrated superior trypanocidal activity against cultured T. cruzi parasites. For example, 4-pyridyl analogues (e.g., 4) exhibited sub-micromolar minimal trypanocidal concentration values $(\mathrm{MTC}=0.6 \mu \mathrm{M})$ while the MTC values for 2-pyridyl (e.g., 3) and 3-pyridyl analogues were typically $\approx 10 \mu \mathrm{M}$, which was similar to the MTC of $\mathbf{1}$ (Table 1). The MTC represents the minimum concentration of test compound required to completely clear $T$. cruzi parasites from $\mathrm{J} 774$ macrophage host cells over a 40-day experiment, with the test compound being administered during the initial 28 days.

The enhanced potency of 4-pyridyl analogues as compared to $\mathbf{1}$ or their regioisomeric analogues was not predictable on the basis of in vitro cruzain activity (Table 1). Nor could the trends be explained as an effect of lysosomotropism, since enhanced potency was observed only for the 4-pyridyl analogues and not for 2- or 3-pyridyl analogues, which have similar $\mathrm{p} K_{\mathrm{a}}$ values.

\begin{tabular}{|c|c|c|c|c|c|}
\hline \multirow[t]{2}{*}{ compound } & \multirow{2}{*}{$\begin{array}{l}\text { cruzain activity } \\
k_{\text {inact }} / K_{\mathrm{i}} \\
\left(\mathrm{s}^{-1} \cdot \mathrm{M}^{-1}\right)\end{array}$} & \multicolumn{2}{|c|}{ TcCYP51 activity } & \multicolumn{2}{|c|}{ T. cruzi growth inhibition } \\
\hline & & $\begin{array}{l}\text { in vitro } K_{\mathrm{D}} \\
(\mathrm{nM})\end{array}$ & $\begin{array}{l}\text { cellular activity } \\
(\mathrm{Y} / \mathrm{N}, \text { conc. })^{\mathrm{a}}\end{array}$ & $\mathrm{MTC}^{\mathrm{b}}(\mu \mathrm{M})$ & $\begin{array}{l}\mathrm{HCS}^{\mathrm{C}} \\
\mathrm{EC}_{90}(\mu \mathrm{M})\end{array}$ \\
\hline 1 & 118,000 & $>2,000$ & $\mathrm{~N}(1.6 \mu \mathrm{M})$ & 8 & 0.10 \\
\hline 2 & 120,000 & - & - & 10 & - \\
\hline 3 & 16,000 & $>2,000$ & $\mathrm{~N}(2.0 \mu \mathrm{M})$ & 8 & 1.85 \\
\hline 4 & 67,300 & $\leq 5$ & $\mathrm{Y}(0.2 \mu \mathrm{M})$ & 0.6 & 0.10 \\
\hline 5 & - & $\leq 5$ & $\mathrm{Y}(5.0 \mu \mathrm{M})$ & $\leq 10^{d}$ & - \\
\hline 6 & n.a. & $>2,000$ & $\mathrm{~N}(2.0 \mu \mathrm{M})$ & $>10$ & $>10$ \\
\hline 7 & n.a. & $>2,000$ & $\mathrm{~N}(0.1 \mu \mathrm{M})$ & $>10$ & $>10$ \\
\hline 8 & n.a. & $\leq 5$ & $\mathrm{Y}(0.1 \mu \mathrm{M})$ & 0.25 & 0.11 \\
\hline 9 & 81,500 & - & - & $5^{e}$ & 0.017 \\
\hline 12 & n.a. & $620 \pm 260$ & - & $>10$ & $>10$ \\
\hline 13 & n.a. & $75 \pm 26$ & - & $1^{f}$ & 3.9 \\
\hline BNZ & - & - & - & 10 & 7.2 \\
\hline POSA & - & $\leq 5$ & $\mathrm{Y}(0.1 \mu \mathrm{M})$ & 0.003 & 2.7 \\
\hline
\end{tabular}

aCompound affects ergosterol biosynthesis at indicated concentration as determined by GC/MS analysis. ${ }^{b}$ Minimum effective concentration that clears $\mathrm{J} 774$ host cells of parasites at day 40 of the experiment, following 28 days of treatment. ${ }^{\circ}$ Concentration that reduces parasite load in $\mathrm{C} 2 \mathrm{C} 12$

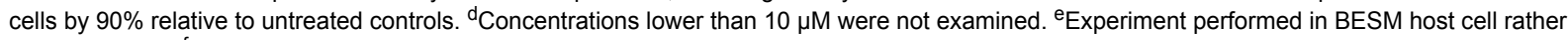
than $\mathrm{J} 774$ cells. ${ }^{\mathrm{f}}$ Read at day 12 following 7 days treatment. 
Instead, we considered that additional target(s) may be responsible for the surprising potency of the 4-pyridyl analogues. Specifically, we were aware that a 4-pyridyl ring comprises the putative heme-binding moiety in a new class of TcCYP51 inhibitors represented by compound 5 (Figure 1). Other structural similarities of $\mathbf{4}$ and $\mathbf{5}$ suggested that compound $\mathbf{4}$ could conceivably bind TcCYP51.

To test the hypothesis that $\mathbf{4}$ may also target TcCYP51, we examined the binding of this compound to TcCYP51 using a UV-vis spectroscopic binding assay described previously [33]. Indeed, compound 4 bound TcCYP51 with an estimated $K_{\mathrm{D}} \leq 5 \mathrm{nM}$, a value comparable to the binding affinity of the known TcCYP51 inhibitor 5 [16]. 2-Pyridyl analogue 3 did not measurably bind $T c$ CYP51 $\left(K_{\mathrm{D}}>2,000 \mathrm{nM}\right.$, Table 1$)$, whereas the corresponding 3-pyridyl congener (not shown) binds about 100 -fold more weakly $\left(K_{\mathrm{D}} \approx 500 \mathrm{nM}\right.$ ) than 4 . These findings were thus consistent with our hypothesis that the 4-pyridyl ring in 4 is involved in binding TcCYP51. The 2-pyridyl ring system in 3 is presumably unable to chelate heme in TcCYP51 due to steric hindrance from the immediately adjacent amide linkage.

\section{Computational docking studies}

We next employed computational docking and a model derived from the crystal structure of TcCYP51 to compare predicted binding modes of $\mathbf{4}$ and $(R)-\mathbf{5}$. The two ligands were docked by using the induced-fit docking protocol with Glide XP [34], and the models were further refined by minimizing the energies of the ligand and surrounding residues (within $5 \AA$ of ligand) using PRIME [35]. Finally, binding scores were computed by using both Glide XP and the MM/GMSA method. Compound 4 was predicted to bind in a similar fashion as $(R)-5$, with the 4-pyridyl ring chelating the heme-iron atom and the tolyl ring at P2 contacting many of the same residues (e.g., Try103, Phe110) predicted to interact with the tryptophan ring of $(R)-5$ (Figure 2A). This same hydrophobic site in TcCYP51 binds the fluoroaryl rings of fluconazole and posaconazole in co-crystal structures [14]. The predicted binding mode of the enantiomer $(S)-5$ was described previously [16] and is distinct from that proposed for $\mathbf{4}$ and $(R)-5$.

Thus, computational docking provides a conceptual picture of how compound $\mathbf{4}$ - notionally a cruzain inhibitor - might also bind TcCYP51. Interestingly, this is not the first time that potent TcCYP51 binding has been discovered in a molecule originally intended for a different target. Buckner and Gelb unexpectedly found that the human protein farnesyltransferase (PFT) inhibitor tipifarnib exerts its antitrypanosomal effects through inhibition of TcCYP51 [36]. Subsequently, these researchers succeeded in divorcing PFT activity from TcCYP51 inhibition in the tipifarnib scaffold, producing new lead compounds with compelling properties [37-39].

\section{Inhibition of mammalian CYPs}

A concern with any inhibitor of TcCYP51 is the potential for cross reactivity with mammalian cytochrome P450 (CYP)
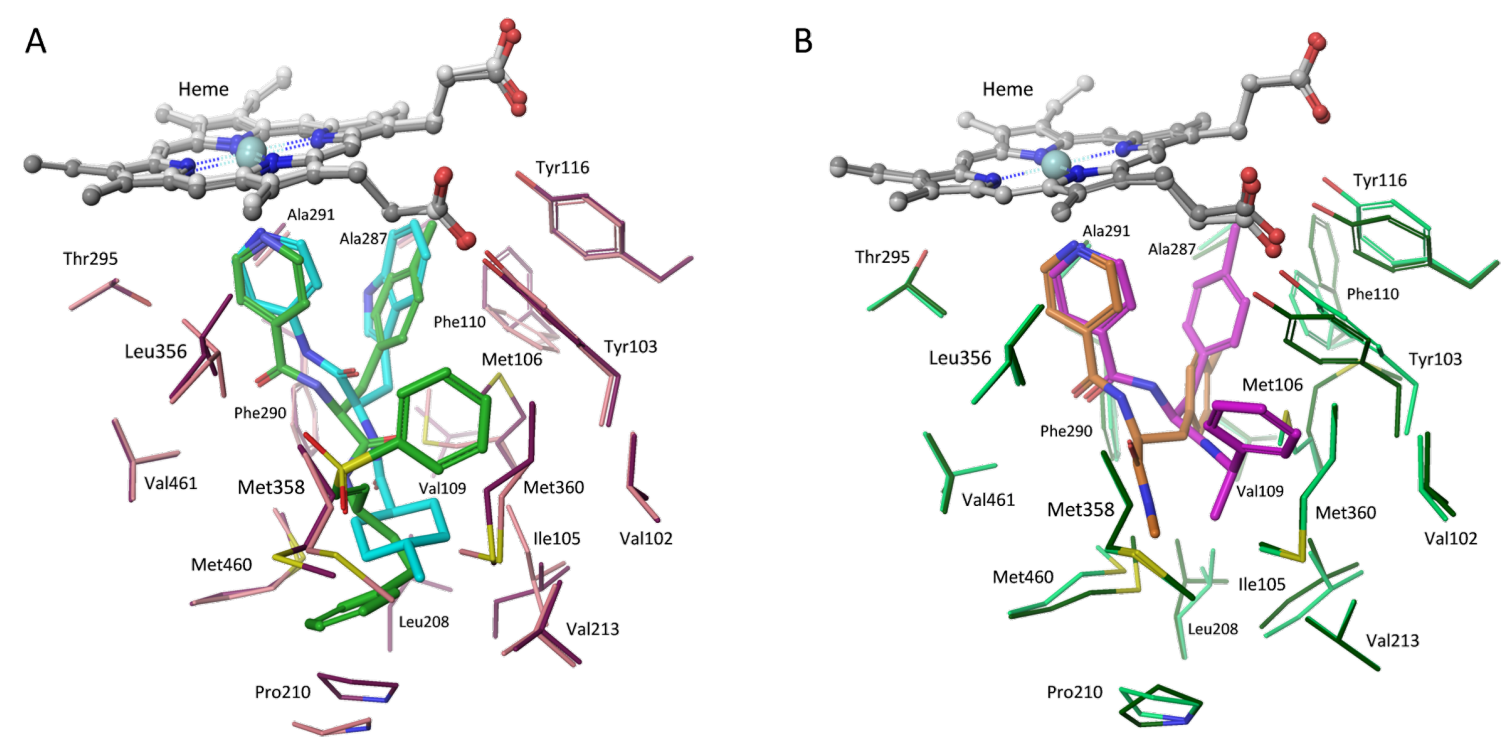

Figure 2: Computational docking models. (A) Predicted binding modes of 4 and $(R)-\mathbf{5}$ bound to TcCYP51. For $\mathbf{4}$, the ligand, the protein, and the heme group are shown in green, pink, and grey, respectively. For $(R)-5$, the ligand, the protein, and the heme group are shown in cyan, purple, and white, respectively. Heme-iron chelation and hydrophobic binding interactions dominate in the models. (B) Predicted binding models of truncated analogues 12 and 13 to TCCYP51. For 12, the ligand, the protein, and the heme group are shown in orange, light green, and light grey, respectively. For 13, the ligand, the protein, and the heme group are shown in magenta, dark green, and dark grey, respectively. 
enzymes, especially those CYPs involved in drug metabolism, like CYP3A4. To assess this risk, we evaluated the inhibitory activities of $\mathbf{4}$ and $\mathbf{1}$ across a panel of relevant mammalian CYP enzymes (Table 2). Both 4 and $\mathbf{1}$ inhibited all CYPs in the panel, with $\mathrm{IC}_{50}$ values generally in the low micromolar range. Although compound $\mathbf{4}$ did inhibit CYP3A4, the potency of inhibition $\left(\mathrm{IC}_{50}=0.8 \mu \mathrm{M}\right)$ was less than that exhibited by the antifungal drug ketoconazole $\left(\mathrm{IC}_{50}=0.086 \mu \mathrm{M}\right)$. It should be noted that the substrate-derived $\mathrm{IC}_{50}$ values from the CYP panel are not directly comparable to the $K_{\mathrm{D}}$ values for binding to $T C$ CYP51. What can be said is that the antitrypanosomal effects of 4 are realized at concentrations $\left(\mathrm{EC}_{90}=0.1 \mu \mathrm{M}\right.$, $\mathrm{MTC}=0.5 \mu \mathrm{M}$ ) well below the in vitro potency of the compound across the CYP panel (average $\mathrm{IC}_{50} \approx 7 \mu \mathrm{M}$ ). Compound 4 thus possesses reasonable selectivity with regard to offtarget CYP inhibition, and represents a reasonable starting point from which further improvements in selectivity may be undertaken.

\begin{tabular}{|c|c|c|c|c|c|}
\hline \multirow{2}{*}{ compound } & \multicolumn{5}{|c|}{$\mathrm{IC}_{50}(\mu \mathrm{M})$} \\
\hline & $1 \mathrm{~A} 2$ & $2 \mathrm{Cg}$ & $2 C 19$ & 2D6 & $3 \mathrm{~A} 4$ \\
\hline 1 & 24 & 32 & 7.6 & 26 & 1.7 \\
\hline 4 & 22 & 5.5 & 3.4 & 2.7 & 0.8 \\
\hline ketoconazole & - & - & - & - & 0.086 \\
\hline
\end{tabular}

Given the similar $\mathrm{IC}_{50}$ values for $\mathbf{1}$ and $\mathbf{4}$ against CYP3A4, we were curious to determine whether $\mathbf{4}$ is an irreversible inhibitor of this enzyme, as is the case for $\mathbf{1}$ [30]. Irreversible inhibition is typically assessed by measuring the activity of microsomal CYPs following pre-incubation with or without NADPH. Consistent with earlier studies [30], compound 1 exhibited irreversible inhibition of CYP3A4 as reflected in a significantly lower $\mathrm{IC}_{50}$ value with NADPH pre-incubation (Table 3). In contrast, compound $\mathbf{4}$ showed behavior typical of reversible inhibition, with no NADPH-dependent shift in the $\mathrm{IC}_{50}$ value. In the case of CYP2C19, both compounds were found to be reversible inhibitors. These results suggest that CYP inhibition by

\begin{tabular}{|c|c|c|c|c|}
\hline \multirow[t]{2}{*}{ compound } & \multicolumn{2}{|l|}{$\begin{array}{l}2 \mathrm{C} 19 \\
\mathrm{IC}_{50}(\mu \mathrm{M})\end{array}$} & \multicolumn{2}{|l|}{$\begin{array}{l}3 \mathrm{~A} 4 \\
\mathrm{IC}_{50}(\mu \mathrm{M})\end{array}$} \\
\hline & +NADPH & -NADPH & +NADPH & -NADPH \\
\hline 1 & 5.54 & 8.22 & 0.0059 & 1.08 \\
\hline 4 & 0.300 & 0.170 & 0.117 & 0.046 \\
\hline
\end{tabular}

4 involves reversible binding of the parent molecule, while the inhibition of CYP3A4 conferred by $\mathbf{1}$ is dependent on initial conversion to a reactive metabolite. Whatever the explanation, reversible inhibition of CYP enzymes (as with 4) is clearly preferable to irreversible inhibition from a drug-safety perspective.

\section{Inhibition of TcCYP51 in live parasites}

We next sought to better define the relative importance of TcCYP51 and cruzain inhibition in the antitrypanosomal effects of compound 4. Since the 2-pyridyl analogue 3 was found to not bind TcCYP51, this compound could serve as a control for the cruzain-derived (and/or other cysteine-protease-derived) effects of 4. To provide controls lacking activity against cysteine proteases, we reduced the vinylsulfone function in analogues $\mathbf{1}$, $\mathbf{3}$, and $\mathbf{4}$ to afford the dihydro analogues 6-8 (Figure 3). As expected, these analogues were devoid of any detectable cruzain inhibitory activity ( $\mathrm{IC}_{50}>50 \mu \mathrm{M}$, Table 1 ). Compounds 3, 4, 7 and 8 thus comprised a set of analogues with complementary activity profiles against the two putative targets: 4 (cruzain and TcCYP51 inhibition), 8 (TcCYP51 inhibition only), 3 (cruzain inhibition only), and 7 (neither activity).

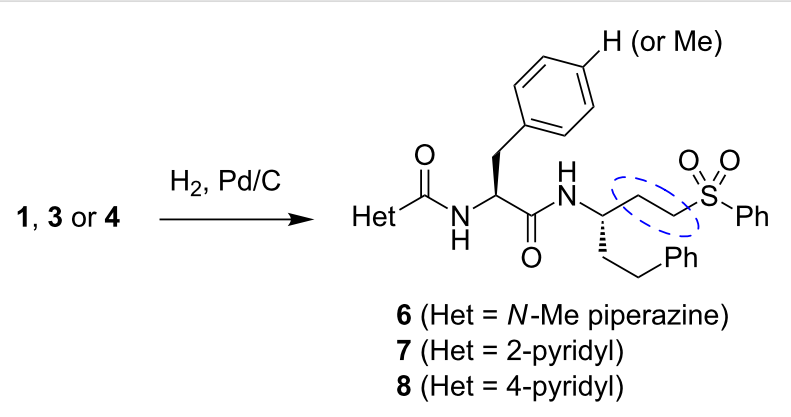

Figure 3: Synthesis of the additional control compound 6-8, the reduced forms of analogues 1,3 , and 4 respectively.

Compounds 3, 4, 7, and 8 were evaluated for potency against intracellular T. cruzi parasites by using two different assays. The reported $\mathrm{EC}_{90}$ values (Table 1) represent compound concentrations required to reduce parasite numbers in $\mathrm{C} 2 \mathrm{C} 12$ host cells by $90 \%$ as compared to untreated controls, as determined by using a high-content imaging-based screening (HCS) approach $[33,40]$. This high-throughput assay provides a rapid measure of the initial acute effects of test compound on parasite viability. The more laborious MTC assay identifies compound concentrations that clear parasites from the host cell, as determined ca. two weeks after the conclusion of a four-week course of treatment. This MTC assay therefore provides a measure of trypanocidal action that cannot be drawn from the more rapid HCS assay. We judge that MTC values are more representative of the therapeutic drug levels that would likely be 
required to produce efficacy in an animal model of Chagas' disease.

The antitrypanosomal effects of compounds $3,4,7$, and 8 were in general agreement with their in vitro activities against the two putative targets (Table 1). Analogue 7, devoid of either activity in vitro, showed no effects on $T$. cruzi parasites in either the HCS or MTC assay. Analogue 3, possessing primarily cysteine-protease-derived effects, was effective in both assays and equipotent to $\mathbf{1}$ in the MTC assay. Putatively dual-targeted analogue $\mathbf{4}$ was about 10 -fold more potent than $\mathbf{1}$ in the MTC assay and equipotent by HCS. Most unexpectedly, we found that compound $\mathbf{8}$, which lacks any cruzain-derived effects of $\mathbf{4}$, was equipotent to 4 by $\mathrm{HCS}$ and 2-4 times more potent than $\mathbf{4}$ in the MTC assay.

The in vitro and cell-based activities of $\mathbf{4}$ and $\mathbf{8}$ suggest TcCYP51 as a relevant target of these compounds. To assess inhibition of TcCYP51 in live parasites we analyzed the sterol composition of intracellular $T$. cruzi parasites treated with test compounds $3-\mathbf{8}, \mathbf{1}$, or posaconazole as a positive control. The analysis was performed by employing GC/MS as reported previously for compound 5 [33]. The GC/MS trace for uninfected host cells establishes that the additional peaks observed in infected cells are of $T$. cruzi origin (peaks labeled a-i, Figure 4). Treatment with the known TcCYP51 inhibitor posaconazole produces an increase in the relative abundance of TcCYP51 substrates lanosterol (f) and eburicol (h) and accordingly, a reduction in the abundance of downstream sterols such as fecosterol (e) and cholesta-7,24-dien-3 $\beta$-ol (a), among others. Treatment with 1 had little effect on sterol composition as expected, whereas treatment with compound $\mathbf{4}$ or $\mathbf{8}$ produced effects very similar to those observed in posaconazole treated parasites (Figure 4 and Supporting Information File 1). The other test compounds evaluated $(\mathbf{3}, \mathbf{6}, \mathbf{7})$ produced no significant change in lipid composition, as expected since these compounds do not inhibit TcCYP51 in vitro (Supporting Information File 1). Test compounds were necessarily studied at concentrations below their MTC, so as to retain a population of viable parasites for analysis.

\section{An activity-based probe reveals an off-target of 1 and 4}

We next sought to evaluate the cysteine-protease-related effects of the various test compounds in T. cruzi parasites. To do this, we designed and synthesized the "clickable" activity-based probe 9 in which a propargyl group (replacing methyl in 1) serves as a chemical handle for conjugation to TAMRA- or biotin-containing reagents (10 and 11, respectively, Figure 5). Probe 9 was found to be equipotent to 1 against cruzain in vitro and retained similar effects against $T$. cruzi parasites in both the

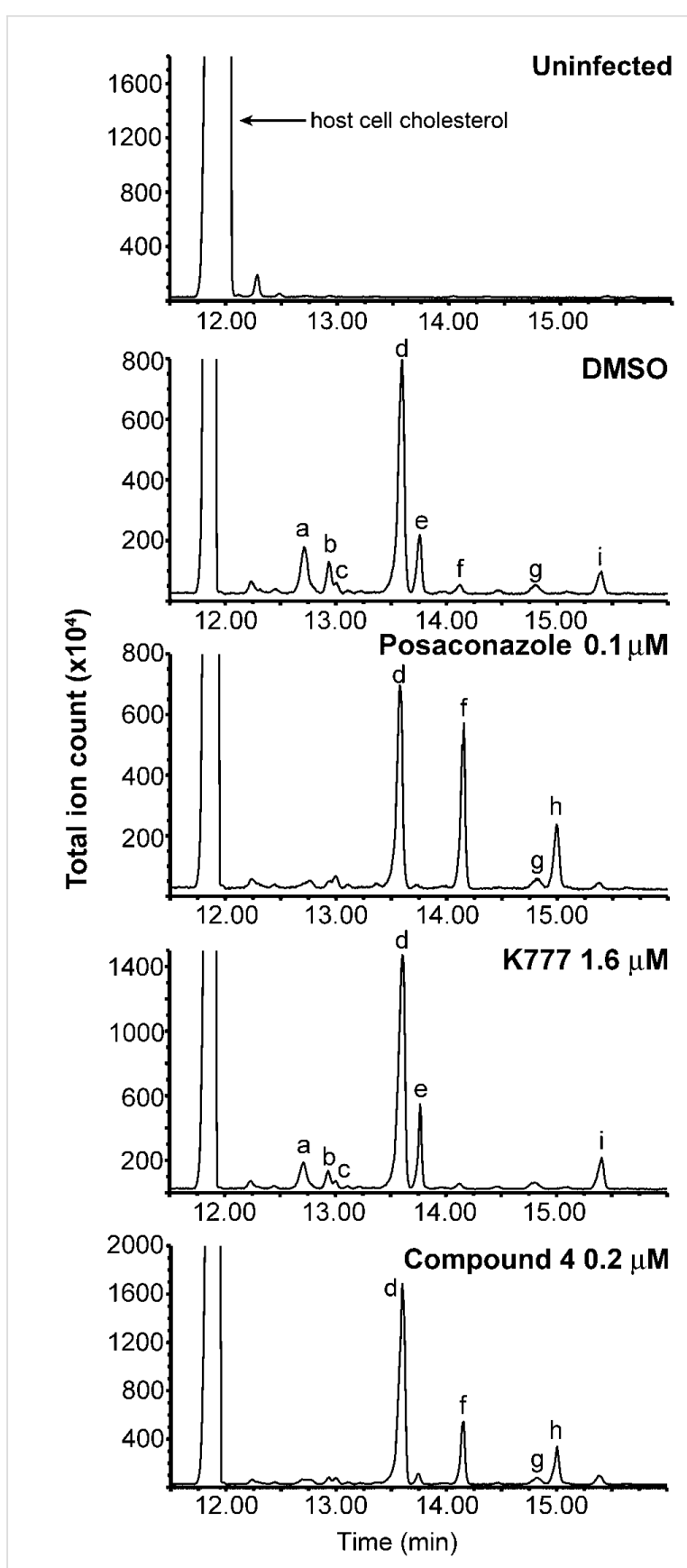

Figure 4: GC/MS analysis of lipid extracts from $T$. cruzi parasites treated with test compounds. DMSO and K777 (1) were used as negative controls; posaconazole served as a positive control. The analysis of 4 was performed concurrently with other CYP51 inhibitors described recently [33] and, thus, the spectra for the controls shown above are reproduced from the earlier report. Spectra of lipid extracts from parasites treated with $\mathbf{3}, \mathbf{6}, \mathbf{7}$, and $\mathbf{8}$ are provided in Supporting Information File 1. Uninfected host cell panel (top) demonstrates that chromatographic peaks labeled $\mathbf{a}$ to $\mathbf{i}$ in subsequent panels are of $T$. cruzi origin. These peaks are assigned as a - cholesta-7,24-dien-3 $\beta-o l,\left[\mathrm{M}^{++}=\mathrm{m} / \mathrm{z}\right.$ 454; b - cholesta-8,24-dien-3 $\beta$-ol (zymosterol), [M] ${ }^{++}=\mathrm{m} / \mathrm{z} 470$; $\mathbf{c}$ 24-methyl-7-en-cholesta-en-3 $\beta$-ol, [M] ${ }^{++}=m / z$ 472; $\mathbf{d}$ - ergosta-7,24-

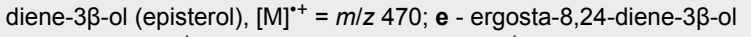
(fecosterol), $[\mathrm{M}]^{*+}=\mathrm{m} / \mathrm{z} 470 ; \mathbf{f}$ - lanosterol, $[\mathrm{M}]^{++}=\mathrm{m} / \mathrm{z}$ 498; $\mathbf{g}$ 4-methylepisterol, [M] ${ }^{++}=m / z 484 ; \mathbf{h}$ - eburicol, $[\mathrm{M}]^{++}=\mathrm{m} / \mathrm{z} 512 ; \mathbf{i}$ -

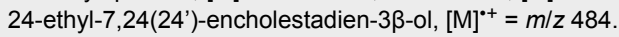


HCS and MTC assays. Thus, the cysteine protease target(s) of 9 in parasite and host cell can reasonably be assumed to be the same as for $\mathbf{1}$ and close analogues such as $\mathbf{4}$.<smiles>C#CCN1CCN(C(=O)NC(Cc2ccccc2)C(=O)N[C@H](/C=C/S(=O)(=O)c2ccccc2)CCc2ccccc2)CC1</smiles><smiles>CCNC(=O)c1ccc(-c2c3ccc(=[N+](C)C)cc-3oc3cc(N(C)C)ccc23)c(C(=O)[O-])c1</smiles><smiles>NCCCCCC(=O)OCCCCCCNC(=O)CCCC[C@H]1SC[C@@H]2NC(=O)N[C@@H]21</smiles>

Figure 5: Chemical structures of compound 9, a "clickable" activitybased probe based on 1 and complementary azide-containing reagents 10 and 11.

Independently, another group recently reported the synthesis of $\mathbf{9}$ and its use to identify putative targets of $\mathbf{1}$ in the related parasite Trypanosoma brucei [41]. Our efforts to similarly identify targets of $\mathbf{1}$ in $T$. cruzi were complicated by the presence of a host-cell protein that was apparently a major target of 9 . In a typical experiment, intracellular T. cruzi amastigotes were treated with 9 for 1 hour, followed by cell lysis, "click" reaction with TAMRA azide 10, and separation/visualization by SDS-PAGE. Regardless of the host cell employed (J774 macrophage, or $\mathrm{C} 2 \mathrm{C} 12$ ), only one prominently labeled band at $\approx 35 \mathrm{kDa}$ was observed in these experiments. This band was attributed to a host-cell protein as it appeared also in analogous experiments employing uninfected cells. In fact, we could not conclusively identify any unique bands of parasitic origin in our experiments, although such bands might well have escaped detection due to lower abundance and labeling below the limit of fluorescence detection.

The discovery of a potential mammalian off-target of probe 9 (and presumably also of $\mathbf{1}$ ) was of considerable interest, so we explored this finding further. To determine if this protein was also a target of $\mathbf{1}$ and $\mathbf{4}$, we conducted competition experiments in $\mathrm{C} 2 \mathrm{C} 12$ cells. Hence, pre-incubation of cells with competitor compound at either $1 \mu \mathrm{M}$ or $10 \mu \mathrm{M}$ for one hour was followed by treatment for one hour with $\mathbf{9}$, followed by cell lysis, conjugation to 10, separation (SDS-PAGE), and detection by rhodamine fluorescence as before. In these experiments, pretreatment with $10 \mu \mathrm{M}$ of compound $\mathbf{1}, \mathbf{3}$, or $\mathbf{4}$ successfully blocked labeling of the $\approx 35 \mathrm{kDa}$ band by probe 9 , thus indicating that these compounds also react with this target (Figure 6). As expected, the nonelectrophilic dihydro forms of $\mathbf{1}$ and 4 (i.e., compounds 6 and 8) did not compete for labeling by 9. Taken together, these results strongly suggest that compounds 1,3 and 4 react irreversibly with the $\approx 35 \mathrm{kDa}$ protein in a process involving the electrophilic vinylsulfone moiety.

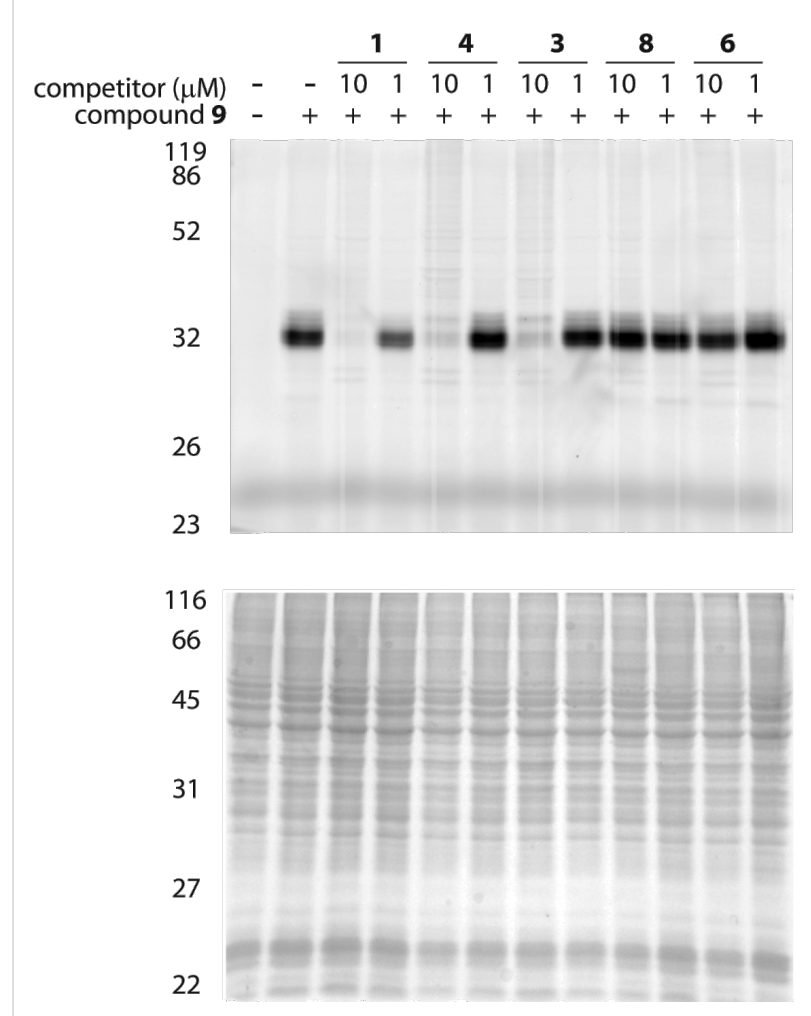

Figure 6: Competitive labeling of host cell $(\mathrm{C} 2 \mathrm{C} 12)$ proteins. Intact cells were labeled with probe 9 following a competitive pre-incubation step with compounds $\mathbf{1}, \mathbf{4}, \mathbf{3}, \mathbf{8}$, or $\mathbf{6}$. After cell lysis, protein adducts of 9 were conjugated to rhodamide-based dye 10 . The gel image at the top shows rhodamine fluorescence. The gel image at the bottom is of the coomassie stained gel. A successfully competed band is observed at $\approx 35 \mathrm{kDa}$, and this was subsequently identified as cathepsin $\mathrm{B}$.

\section{Chemical proteomics}

We next applied mass spectrometric analysis to identify the $\approx 35 \mathrm{kDa}$ band, which was an apparent target of the electrophilic inhibitors described above. To enrich for this protein, $\mathrm{C} 2 \mathrm{C} 12$ cells were labeled with 9 as before and then reacted with the biotin azide reagent $\mathbf{1 1}$, followed by biotin capture onto streptavidin beads. A base-cleavable ester function was introduced in the linker of $\mathbf{1 1}$, and this allowed enriched proteins to be released from beads by treatment with sodium hydroxide. The liberated proteins were separated by SDS-PAGE, and the relevant band at $\approx 35 \mathrm{kDa}$ extracted from the gel. An in-gel trypsin digest [42] was followed by UPLC separation of the 
tryptic peptides and MS/MS analysis using a hybrid linear iontrap-Orbitrap mass spectrometer. Tandem mass spectra acquired were searched against the UniProtKb database employing ProteinProspector; four MS/MS spectra corresponding to the same peptide sequence were identified (Figure 7). This sequence was found to correspond to the tryptic peptide spanning resides S264-R281 from mouse cathepsin B (uniprot $\mathrm{P} 10605)$. Significantly, this peptide was not found in analogous experiments where pre-incubation with 1 or 4 (at $10 \mu \mathrm{M}$ ) preceded labeling with $\mathbf{9}$, nor in an experiment in which $\mathbf{9}$ was not added. Thus, cathepsin B is very likely the host-cell protein target of compounds $\mathbf{1}$ and $\mathbf{4}$ identified in the competition experiments with compound $\mathbf{9}$.

The identification of cathepsin B as a relevant cellular off-target of $\mathbf{1}$ and $\mathbf{4}$ is potentially significant. On the one hand, the HCS EC $_{90}$ values of $\mathbf{1}$ and $\mathbf{4}$ are at least 10 -fold lower than the concentrations of these compounds used in the competition experiments. Thus, one might expect to achieve effects on parasite viability before significant inhibition of cathepsin B is conferred. On the other hand, the MTC for $\mathbf{1}(8 \mu \mathrm{M})$ lies squarely in the range at which the compound effectively competes for cathepsin B labeling by $\mathbf{9}$. Thus, if micromolar concentrations of $\mathbf{1}$ are indeed required to achieve a therapeutic effect in animals, one might well be concerned about the effects on host cathepsin B. Thus, the experiments with 9 identified a potential off-target while also providing an experimental means for testing the effects of new analogues on this off-target in a relevant, cellular context.

\section{Defining a new lead scaffold for TcCYP51 inhibition}

The similar cellular potencies of $\mathbf{4}$ and its reduced form $\mathbf{8}$ suggest that cruzain inhibition plays a relatively minor role in the trypanocidal action of 4 . To a first approximation, the cruzain- and TcCYP51-derived effects of $\mathbf{4}$ should be similar to those of its close analogues $3(\mathrm{MTC} \approx 10 \mu \mathrm{M})$ and 8 (MTC $\approx$ $0.25 \mu \mathrm{M})$, respectively. Unless the effects of inhibiting both targets are synergistic, which is not supported by the data, there would appear to be little benefit gained by combining a relatively weak cruzain-derived effect with a much more potent insult conferred by TcCYP51 inhibition. Moreover, it now seems likely that electrophilic compounds such as $\mathbf{1}$ and $\mathbf{4}$ may be partially consumed in nonproductive reactions with host-cell proteases (e.g., cathepsin B) and/or other cytosolic nucleophiles (e.g., glutathione). This possibility is supported by our competitive labeling experiments (Figure 6) and by in vitro studies employing physiological concentrations of glutathione (Supporting Information File 1). With regard to the inhibitor chemotypes covered here, there appears to be little rationale for targeting both cruzain and TcCYP51. On the other hand, the surprising potency of analogue $\mathbf{8}$ does suggest this as a new lead scaffold for the development of novel TcCYP51 inhibitors.

We next sought to define the minimal pharmacophore within $\mathbf{8}$ required for inhibition of TCCYP51 in vitro and antitrypanosomal effects in whole cells. We therefore synthesized truncated analogues of $\mathbf{8}$, such as $\mathbf{1 2}$ and $\mathbf{1 3}$ (Figure 1). These compounds retain the 4-pyridyl ring and neighboring tolyl side

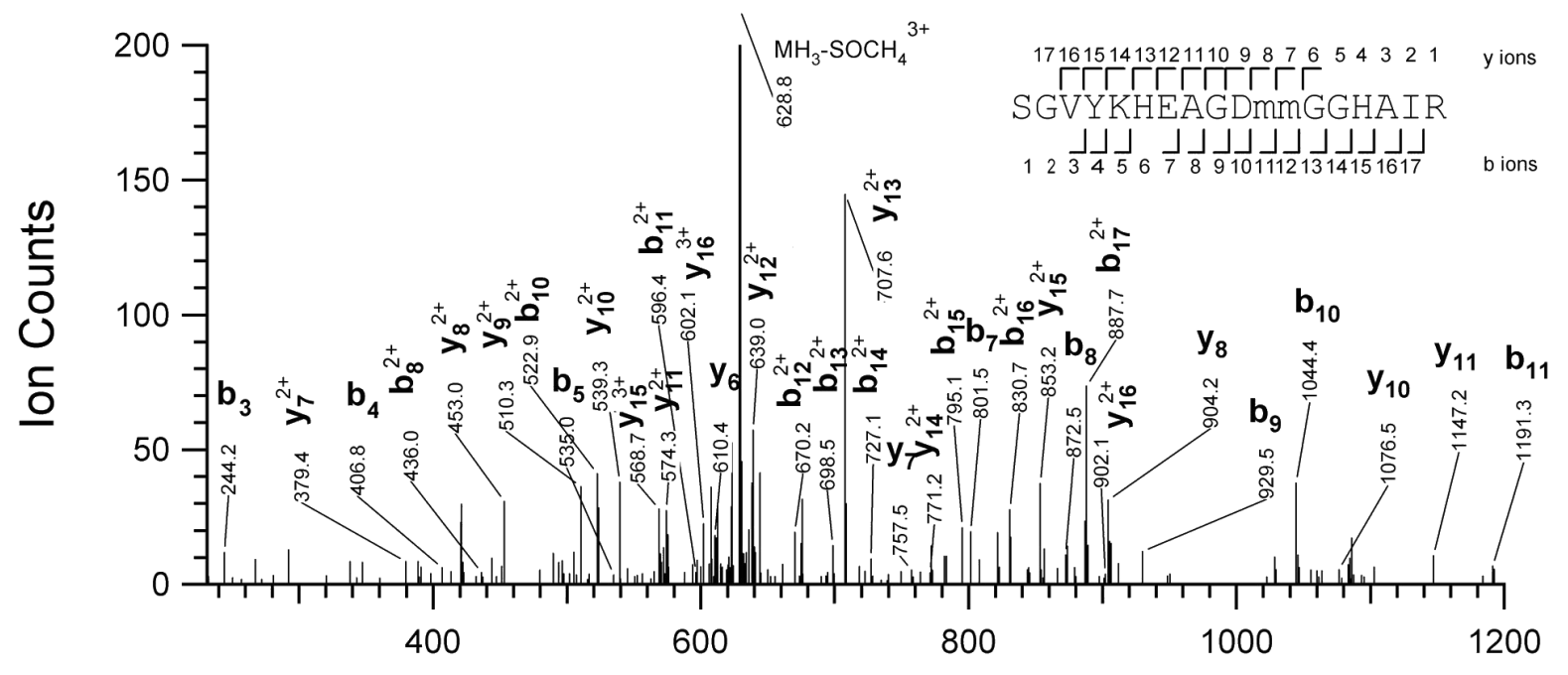

$m / z$

Figure 7: MS/MS spectrum of the tryptic peptide S264-R281 from mouse cathepsin B, identified in pull-down experiments employing compound 9 in $\mathrm{C} 2 \mathrm{C} 12$ cells. Observed sequence ions are labeled $(\mathrm{m}=$ oxidized methionine). 
chain of $\mathbf{8}$ while dispensing with those substituents further removed from the putative heme-binding moiety. Interestingly, the truncated analogues $\mathbf{1 2}$ and $\mathbf{1 3}$ bound TcCYP51 significantly more weakly than 4 or 8 (Table 1), suggesting that side chains relatively far removed from the 4-pyridyl ring nonetheless play an important role in binding.

Computational docking of $\mathbf{1 2}$ and $\mathbf{1 3}$ provided some insight into the observed binding trends. Analogue 13 adopts a docking pose very similar to 4 with respect to the 4-pyridyl and tolyl ring systems. When compared to the poses for $\mathbf{4}$ or $\mathbf{1 3}$, the tolyl ring in $\mathbf{1 2}$ projects much less deeply into the aromatic pocket formed by Phe110 and Tyr103 (Figure 2). Neither 12 nor 13 form interactions with more distal residues (e.g., Leu208, Pro210) that are predicted to form productive contacts with 4. Thus, a larger number of hydrophobic contacts and better orientation of some side chains may explain the binding trends for $\mathbf{4}$, 12, and 13. Interestingly, the rank-order binding affinities of $\mathbf{4}$, $\mathbf{1 2}$, and $\mathbf{1 3}$ were correctly predicted by the MM-GBSA method applied to the binding models of these compounds (Supporting Information File 1). This suggests that such models could serve to aid in the design of new TcCYP51 inhibitors derived from this scaffold.

The antitrypanosomal activities of analogues $\mathbf{1 2}$ and $\mathbf{1 3}$ could be correlated with their in vitro binding affinities for TcCYP51 (Table 1). Hence, analogue $13\left(K_{\mathrm{D}}=75 \mathrm{nM}\right)$ shows reduced antitrypanosomal activity when compared to $8\left(K_{\mathrm{D}} \approx 5 \mathrm{nM}\right)$. Still weaker-binding analogue $12\left(K_{D}=620 \mathrm{nM}\right)$ exhibited no antitrypanosomal effect at the highest concentration examined $(10 \mu \mathrm{M})$. Thus, compound $\mathbf{1 3}$ can be considered to represent a "minimal pharmacophore" that retains reasonable affinity for $T c$ CYP51 in vitro while also conferring an effect on $T$. cruzi parasites in culture. Future work will focus on further refining the in vitro and cellular potency of this scaffold, with compound $\mathbf{1 3}$ serving as a chemical departure point.

\section{Conclusion}

Structure-activity studies are often conducted with the underlying assumption that molecular mechanisms are the same within congeneric analogue series. This assumption is reinforced when activity in biochemical assays can be correlated with cell-based activity. Of course perfect correlation is rarely observed, even when a series is in fact "on-target". Especially perilous is the construction of mechanistic hypotheses based solely on the correlation of in vitro biochemical assay data with gross phenotypic endpoints such as parasite growth inhibition or cell death. As demonstrated here, even seemingly trivial structural changes within a congeneric SAR series can produce analogues with disparate molecular mechanisms of action. Advisable approaches to deal with these uncertainties include the use of cell-based counter assays that can detect action at specific targets or signaling pathways of interest. Activity-based probes can serve as useful tools to verify on-target action during the course of chemical optimization campaigns.

\section{Supporting Information}

The Supporting Information features a table with experimentally determined and computationally predicted binding affinities, additional GC/MS spectra from lipid-analysis studies, time courses for reaction of compounds $\mathbf{1}$ and $\mathbf{6}$ with glutathione in vitro, and synthetic schemes for analogues $4,9,11,12$, and 13 , as well as experimental procedures.

\section{Supporting Information File 1}

Figures, schemes, and experimental procedures. [http://www.beilstein-journals.org/bjoc/content/ supplementary/1860-5397-9-3-S1.pdf]

\section{Acknowledgements}

The authors acknowledge research support from the Sandler Foundation (to ARR), NIH RO1 AI095437 (to LMP), Conselho Nacional de Desenvolvimento Cientifico e Tecnologico and FIOCRUZ (to CMC). JBJ was supported by NIH RO1 AI74824 (to Prof. Ortiz de Montellano, UCSF). Mass spectrometry was provided by the Bio-Organic Biomedical Mass Spectrometry Resource at UCSF (A.L. Burlingame, Director) and supported by the Biomedical Technology Research Centers program of the NIH National Institute of General Medical Sciences, NIH NIGMS 8P41GM103481. MPJ is a consultant to Schrodinger, LLC.

\section{References}

1. de Souza, W. Microbes Infect. 2007, 9, 544-545. doi:10.1016/j.micinf.2006.12.014

2. Urbina, J. A. Mem. Inst. Oswaldo Cruz 2009, 104 (Suppl. 1), 311-318. doi:10.1590/S0074-02762009000900041

3. Castro, J. A.; de Mecca, M. M.; Bartel, L. C. Hum. Exp. Toxicol. 2006, 25, 471-479. doi:10.1191/0960327106het653oa

4. Renslo, A. R.; McKerrow, J. H. Nat. Chem. Biol. 2006, 2, 701-710. doi:10.1038/nchembio837

5. McKerrow, J. H.; Doyle, P. S.; Engel, J. C.; Podust, L. M.; Robertson, S. A.; Ferreira, R.; Saxton, T.; Arkin, M.; Kerr, I. D.; Brinen, L. S.; Craik, C. S. Mem. Inst. Oswaldo Cruz 2009, 104 (Suppl. 1), 263-269. doi:10.1590/S0074-02762009000900034

6. Urbina, J. A. J. Mol. Med. (Heidelberg, Ger.) 1999, 77, 332-338. doi:10.1007/s001090050359

7. McKerrow, J. H.; Engel, J. C.; Caffrey, C. R. Bioorg. Med. Chem. 1999, 7, 639-644. doi:10.1016/S0968-0896(99)00008-5

8. Eakin, A. E.; McGrath, M. E.; McKerrow, J. H.; Fletterick, R. J.; Craik, C. S. J. Biol. Chem. 1993, 268, 6115-6118. 
9. McKerrow, J. H.; McGrath, M. E.; Engel, J. C. Parasitol. Today 1995, 11, 279-282. doi:10.1016/0169-4758(95)80039-5

10. McGrath, M. E.; Eakin, A. E.; Engel, J. C.; McKerrow, J. H.; Craik, C. S.; Fletterick, R. J. J. Mol. Biol. 1995, 247, 251-259. doi:10.1006/jmbi.1994.0137

11. Buckner, F. S.; Joubert, B. M.; Boyle, S. M.; Eastman, R. T.; Verlinde, C. L. M. J.; Matsuda, S. P. T. Mol. Biochem. Parasitol. 2003, 132, 75-81. doi:10.1016/j.molbiopara.2003.07.004

12. Hankins, E. G.; Gillespie, J. R.; Aikenhead, K.; Buckner, F. S. Mol. Biochem. Parasitol. 2005, 144, 68-75. doi:10.1016/j.molbiopara.2005.08.002

13. Podust, L. M.; von Kries, J. P.; Eddine, A. N.; Kim, Y.; Yermalitskaya, L. V.; Kuehne, R.; Ouellet, H.; Warrier, T.; Alteköster, M.; Lee, J.-S.; Rademann, J.; Oschkinat, H.; Kaufmann, S. H. E.; Waterman, M. R. Antimicrob. Agents Chemother. 2007, 51, 3915-3923. doi:10.1128/AAC.00311-07

14. Chen, C.-K.; Leung, S. S. F.; Guilbert, C.; Jacobson, M. P.; McKerrow, J. H.; Podust, L. M. PLoS Negl. Trop. Dis. 2010, 4, e651. doi:10.1371/journal.pntd.0000651

15. Urbina, J. A. Acta Trop. 2010, 115, 55-68. doi:10.1016/j.actatropica.2009.10.023

16. Doyle, P. S.; Chen, C.-K.; Johnston, J. B.; Hopkins, S. D.; Leung, S. S. F.; Jacobson, M. P.; Engel, J. C.; McKerrow, J. H.; Podust, L. M. Antimicrob. Agents Chemother. 2010, 54, 2480-2488. doi:10.1128/AAC.00281-10

17. Harth, G.; Andrews, N.; Mills, A. A.; Engel, J. C.; Smith, R.; McKerrow, J. H. Mol. Biochem. Parasitol. 1993, 58, 17-24. doi:10.1016/0166-6851(93)90086-D

18. Roush, W. R.; Cheng, J.; Knapp-Reed, B.; Alvarez-Hernandez, A.; McKerrow, J. H.; Hansell, E.; Engel, J. C. Bioorg. Med. Chem. Lett. 2001, 11, 2759-2762. doi:10.1016/S0960-894X(01)00566-2

19. Huang, L.; Lee, A.; Ellman, J. A. J. Med. Chem. 2002, 45, 676-684. doi:10.1021/jm010333m

20. Greenbaum, D. C.; Mackey, Z.; Hansell, E.; Doyle, P.; Gut, J.; Caffrey, C. R.; Lehrman, J.; Rosenthal, P. J.; McKerrow, J. H.; Chibale, K. J. Med. Chem. 2004, 47, 3212-3219. doi:10.1021/jm030549j

21. Jaishankar, P.; Hansell, E.; Zhao, D.-M.; Doyle, P. S.; McKerrow, J. H.; Renslo, A. R. Bioorg. Med. Chem. Lett. 2008, 18, 624-628. doi:10.1016/j.bmcl.2007.11.070

22. Brak, K.; Doyle, P. S.; McKerrow, J. H.; Ellman, J. A. J. Am. Chem. Soc. 2008, 130, 6404-6410. doi:10.1021/ja710254m

23. Chen, Y. T.; Lira, R.; Hansell, E.; McKerrow, J. H.; Roush, W. R. Bioorg. Med. Chem. Lett. 2008, 18, 5860-5863. doi:10.1016/j.bmcl.2008.06.012

24. Bryant, C.; Kerr, I. D.; Debnath, M.; Ang, K. K. H.; Ratnam, J.; Ferreira, R. S.; Jaishankar, P.; Zhao, D.; Arkin, M. R.; McKerrow, J. H.; Brinen, L. S.; Renslo, A. R. Bioorg. Med. Chem. Lett. 2009, 19, 6218-6221. doi:10.1016/j.bmcl.2009.08.098

25. Brak, K.; Kerr, I. D.; Barrett, K. T.; Fuchi, N.; Debnath, M.; Ang, K.; Engel, J. C.; McKerrow, J. H.; Doyle, P. S.; Brinen, L. S.; Ellman, J. A. J. Med. Chem. 2010, 53, 1763-1773. doi:10.1021/jm901633v

26. Mott, B. T.; Ferreira, R. S.; Simeonov, A.; Jadhav, A.; Ang, K. K.-H.; Leister, W.; Shen, M.; Silveira, J. T.; Doyle, P. S.; Arkin, M. R.; McKerrow, J. H.; Inglese, J.; Austin, C. P.; Thomas, C. J.; Shoichet, B. K.; Maloney, D. J. J. Med. Chem. 2010, 53, 52-60. doi:10.1021/jm901069a
27. Beaulieu, C.; Isabel, E.; Fortier, A.; Massé, F.; Mellon, C.; Méthot, N.; Ndao, M.; Nicoll-Griffith, D.; Lee, D.; Park, H.; Black, W. C. Bioorg. Med. Chem. Lett. 2010, 20, 7444-7449. doi:10.1016/j.bmcl.2010.10.015

28. Engel, J. C.; Doyle, P. S.; Hsieh, I.; McKerrow, J. H. J. Exp. Med. 1998, 188, 725-734. doi:10.1084/jem.188.4.725

29. Barr, S. C.; Warner, K. L.; Kornreic, B. G.; Piscitelli, J.; Wolfe, A.; Benet, L.; McKerrow, J. H. Antimicrob. Agents Chemother. 2005, 49, 5160-5161. doi:10.1128/AAC.49.12.5160-5161.2005

30. Jacobsen, W.; Christians, U.; Benet, L. Z. Drug Metab. Dispos. 2000, 28, 1343-1351.

31. Falgueyret, J.-P.; Desmarais, S.; Oballa, R.; Black, W. C.; Cromlish, W.; Khougaz, K.; Lamontagne, S.; Massé, F.; Riendeau, D.; Toulmond, S.; Percival, M. D. J. Med. Chem. 2005, 48, 7535-7543. doi:10.1021/jm0504961

32. Robichaud, J.; Black, W. C.; Thérien, M.; Paquet, J.; Oballa, R. M.; Bayly, C. I.; McKay, D. J.; Wang, Q.; Isabel, E.; Léger, S.; Mellon, C.; Kimmel, D. B.; Wesolowski, G.; Percival, M. D.; Massé, F.; Desmarais, S.; Falgueyret, J.-P.; Crane, S. N. J. Med. Chem. 2008, 51, 6410-6420. doi:10.1021/jm800610j

33. Gunatilleke, S. S.; Calvet, C. M.; Johnston, J. B.; Chen, C. K.; Erenburg, G.; Gut, J.; Engel, J. C.; Ang, K. K.; Mulvaney, J.; Chen, S.; Arkin, M. R.; McKerrow, J. H.; Podust, L. M. PLoS Negl. Trop. Dis. 2012, 6, e1736.

34. Sherman, W.; Day, T.; Jacobson, M. P.; Friesner, R. A.; Farid, R. J. Med. Chem. 2006, 49, 534-553. doi:10.1021/jm050540c

35. Zhu, K.; Shirts, M. R.; Friesner, R. A.; Jacobson, M. P. J. Chem. Theory Comput. 2007, 3, 640-648. doi:10.1021/ct600129f

36. Hucke, O.; Gelb, M. H.; Verlinde, C. L. M. J.; Buckner, F. S. J. Med. Chem. 2005, 48, 5415-5418. doi:10.1021/jm050441z

37. Kraus, J. M.; Verlinde, C. L. M. J.; Karimi, M.; Lepesheva, G. I.; Gelb, M. H.; Buckner, F. S. J. Med. Chem. 2009, 52, 1639-1647. doi:10.1021/jm801313t

38. Chennamaneni, N. K.; Arif, J.; Buckner, F. S.; Gelb, M. H. Bioorg. Med. Chem. Lett. 2009, 19, 6582-6584. doi:10.1016/j.bmcl.2009.10.029

39. Kraus, J. M.; Tatipaka, H. B.; McGuffin, S. A.; Chennamaneni, N. K.; Karimi, M.; Arif, J.; Verlinde, C. L. M. J.; Buckner, F. S.; Gelb, M. H. J. Med. Chem. 2010, 53, 3887-3898. doi:10.1021/jm9013136

40. Engel, J. C.; Ang, K. K. H.; Chen, S.; Arkin, M. R.; McKerrow, J. H.; Doyle, P. S. Antimicrob. Agents Chemother. 2010, 54, 3326-3334. doi:10.1128/AAC.01777-09

41. Yang, P.-Y.; Wang, M.; He, C. Y.; Yao, S. Q. Chem. Commun. 2012, 48, 835-837. doi:10.1039/c1cc16178d

42. Rosenfeld, J.; Capdevielle, J.; Guillemot, J. C.; Ferrara, P. Anal. Biochem. 1992, 203, 173-179. doi:10.1016/0003-2697(92)90061-B 


\section{License and Terms}

This is an Open Access article under the terms of the Creative Commons Attribution License

(http://creativecommons.org/licenses/by/2.0), which permits unrestricted use, distribution, and reproduction in any medium, provided the original work is properly cited.

The license is subject to the Beilstein Journal of Organic Chemistry terms and conditions:

(http://www.beilstein-journals.org/bjoc)

The definitive version of this article is the electronic one which can be found at:

doi:10.3762/bjoc. 9.3 